\title{
Investigation of depot neuroleptic injection site reactions
}

\author{
Julie C. Jones, Jennifer C. Day, John R. Taylor and \\ Christopher S. Thomas
}

\begin{abstract}
Aims and method A cross-sectional survey was performed on 318 patients receiving depot medication. The presence or absence of a depot site reaction was recorded by psychiatric nursing staff on a standardised form.

Results Seventeen per cent of patients were found to have clinically significant depot site reactions. Such reactions were associated with increased frequency of injection and increased total volume of depot administered in the previous 12 months. The severity of a depot site reaction was unrelated to the concentration of depot preparation administered.

Clinical implications Depot site reactions may be reduced by maximising the interval between injections and using low volume (highly concentrated) preparations of depot neuroleptic medication.
\end{abstract}

The use of depot neuroleptics in patients suffering from schizophrenia has been associated with improved compliance and reduced rates of relapse (Hirsch et al, 1973; Gottfries \& Green, 1974: Glazer \& Kane, 1992). However, depot administration has been associated with a number of complications at the site of injection including nodules and indurations, muscle granulomas, fibrosis, abscess formation and the accumulation of oil after repeated injections (Starmark et al, 1980; McCreadie et al, 1979; Belanger-Annable, 1985; Hamann et al, 1990). Such adverse events are distressing to the patient and may lead to non-compliance.

Hay (1995) found that $19 \%$ of patients receiving depots experienced significant problems at the site of injection over a 22-week period. These reactions were more likely to be associated with concentrated depot preparations, higher doses, larger volumes, weekly injections, prolonged treatment, older age and with the prescription of haloperidol decanoate or zuclopenthixol decanoate.

\section{The study}

The present study aimed to determine the prevalence of depot reactions and the relation- ship between reactions and other related variables such as dose, volume, concentration and frequency of injection, age, gender and body mass index. All patients prescribed depot neuroleptic medication attending the depot clinic at Withington Hospital in south Manchester and from a defined catchment area of south Liverpool were included in the study. All patients who participated gave informed consent, and the study was approved by the local ethics committees. The following demographic and clinical details were recorded: age, gender, case note diagnosis, date of first episode, dose and frequency of depot and all other current medication. Details relating to depot administration were systematically collected on a standard form (available from the author upon request), including the volume of depot administered at the time of survey, total volume of depot administered in the previous year, total number of injections administered in the previous year and any difficulty with injection.

The nurses in Liverpool and Manchester who normally administered the depot injections were asked to participate in the study and were shown how to rate the presence or absence of a depotsite reaction on the standardised form. They were asked to rate the site of the injection for skin thickening, infection/erythema, nodules/ lumps, bleeding, pain and tenderness experienced as a result of the injection. All of these items were rated on a four-point Likert scale from zero (none) to four (severe). Because of the distance between the two centres no formal assessment of interrater reliability was conducted.

In order to investigate the possible contribution of obesity to depot site complications, body mass and height were noted in Manchester only (weight and height were not routinely recorded in Liverpool) and the body mass index was calculated. Depot doses were converted to flupenthixol twice weekly equivalent doses using the equivalence table in the British National Formulary (Number 31, March 1996). Chlorpromazine equivalents were then calculated using standard methods (Davis, 1974; Foster, 1989). Clinically 
significant depot reactions were judged as any reaction which scored at least two on the Likert scale. The data were entered into a database and analysed on SPSS for Windows.

\section{Findings}

\section{Subject details}

One hundred and fourteen (36\%) patients from Liverpool and 204 (64\%) from south Manchester took part in the study. Two patients in south Manchester declined to take part. There were 196 male and 122 female patients with a mean age of 43 years (s.d. $=12$, range $=18$ to 76 years). Two hundred and sixty-two $(83 \%)$ had a case note diagnosis of schizophrenia; $24(7.5 \%)$ had an affective disorder; 20 (6.3\%) had a schizoaffective disorder; and a further eight $(2.5 \%)$ had diagnoses varying from organic psychosis, obsessive-compulsive disorder and temporal lobe epilepsy. The diagnosis was not ascertained for four patients due to missing case notes. The mean age at first episode of illness was 28 years (s.d. $=9.1$, range $=12$ to 68 years).

\section{Prevalence of depot site reactions}

Side-effects such as bleeding and pain after injection, rated one on the Likert scale, were common and thus the following results refer only to depot site reactions which scored at least two. as this was viewed as a clinically significant depot site reaction. Table 1 shows the number of patients prescribed each depot who experienced a clinically significant depot site reaction. Haloperidol decanoate was associated with the highest proportion of depot site reactions, but this proportion was not significantly different from the other four depot preparations. The overall prevalence of clinically significant depot site reaction was $17 \%$.

Clinically significant depot site reactions were caused by pain $(8.2 \%)$, bleeding $(6.9 \%)$, nodules $(4.4 \%)$ and skin thickening (3.5\%). Clinically significant erythema was not present in any of the patients investigated.
Relationship between depot site reactions and other variables

Clinically significant depot site reactions were associated with greater volumes of depot and greater numbers of injections administered during the previous 12 months (Mantel-Haenszel (for linear association) $\chi^{2}=6.10$, d.f. $=1, P=0.01$ and 7.24, d.f. $=1, P<0.01$, respectively). There was a highly significant relationship between total volume of depot administered in the past 12 months and frequency of injection (Spearman $R=0.56, P<0.001)$. Ordinary concentrations of depot injection were less likely to be associated with depot site reactions when compared with concentrated and low volume preparations (Mantel-Haenszel (for linear association) $\chi^{2}=5.36$, d.f. $=1, P=0.02$ ). However, patients prescribed highly concentrated depot preparations were prescribed a significantly higher number of injections (ordinary concentration $=17.1$, concentrated $=20.8$ and highly concentrated $=29.7$ injections per year) than the other two groups (ANOVA $F(2,304)=22.9, P<0.001)$ and also received a significantly higher volume of depot preparation in the previous year (ordinary concentration= 27.6, concentrated $=24.4$ and highly concentrated $=43.4 \mathrm{ml}$ per year) than the other groups (ANOVA $F(2,308)=10.2, P<0.001)$.

When the severity (sum of Likert scores) of a depot site reaction was analysed after controlling for the volume of depot received in the past 12 months, no significant difference was found between low and higher concentrations of depot.

As flupenthixol decanoate was the most frequently prescribed depot and was available in three concentration types $(20 \mathrm{mg} / \mathrm{ml}, 100 \mathrm{mg}$ / $\mathrm{ml}, 200 \mathrm{mg} / \mathrm{ml}$ ) the analysis was repeated and restricted to flupenthixol decanoate. As with the whole group there was a trend for more severe depot site reactions to occur with increasing concentration of preparation (Mantel-Haenszel $\chi^{2}=3.2, P=0.07$ ); however, when the volume of depot received in the past 12 months was controlled, there was no significant difference between the three preparations of flupenthixol decanoate.

There was no relationship between depot site reactions, and the dosage of depot (as measured

Table 1. Prevalence of clinically significant depot site reactions

\begin{tabular}{llllll}
\hline Clinically significant & $\begin{array}{l}\text { Flupenthixol } \\
\text { decanoate, } \\
\text { reaction }\end{array}$ & $\begin{array}{l}\text { Fluphanzine } \\
\text { decanoate, } \\
\boldsymbol{n}(\%)\end{array}$ & $\begin{array}{l}\text { Pipothiazine } \\
\text { palmitate, } \\
\boldsymbol{n}(\%)\end{array}$ & $\begin{array}{l}\text { Zuclopenthixol } \\
\text { decanoate, } \\
\boldsymbol{n}(\%)\end{array}$ & $\begin{array}{l}\text { Haloperidol } \\
\text { decanoate, } \\
\boldsymbol{n}(\%)\end{array}$ \\
\hline Absent & $160(83)$ & $41(85)$ & $21(88)$ & $18(82)$ & $21(75)$ \\
Present & $34(17)$ & $7(15)$ & $3(12)$ & $4(18)$ & $7(25)$ \\
Total & $194(100)$ & $48(100)$ & $24(100)$ & $22(100)$ & $28(100)$ \\
\hline
\end{tabular}


by chlorpromazine equivalents), concurrent medication, body mass index, gender or age of subject.

\section{Comment}

Some care should be exercised in interpreting our results as the numbers of patients receiving depot preparations other than flupenthixol decanoate were small and the interrater reliability of the nursing staff who rated the presence or absence of a clinically significant depot site reaction was not formally assessed. There was also some uncertainty about whether the subjects from Manchester and Liverpool were representative of patients receiving depot medication elsewhere in the UK.

If these caveats are put to one side then this study found the prevalence of localised adverse reactions to depot neuroleptics to be $17 \%$, which is similar to the $19 \%$ found by Hay (1995). Such reactions were associated with increased frequency of injections and increased total volume of depot administered in the previous 12 months. Flupenthixol and fluphenazine decanoate were the most commonly prescribed depots. As in Hay's (1995) study haloperidol and zuclopenthixol decanoate were associated with a slightly higher proportion of depot-site reactions, but this increase was not statistically significant.

Hay (1995) and Svendsen (1989) observed more depot site reactions when concentrated preparations were used, but they did not control for the volume of depot administered in the previous 12 months. In this study we found a significant increase in clinically significant depot-site reactions with higher concentrations of depot, but also found that those patients receiving concentrated preparations had more frequent injections and a significantly higher volume of depot administered in the previous 12 months. When the analysis was repeated adjusting for the volume of depot administered in the past 12 months, there was no significant relationship between the severity of depot site reaction and concentration of depot.

If our findings are replicated, then there may be a case for increasing the interval between depot neuroleptic injections and using low volume (highly concentrated) preparations in order to reduce the administration of high volumes which appear to increase the risk of clinically significant depot-site reactions.

\section{Acknowledgements}

Thanks are due to Professor A. Burns for helpful comments on an earlier draft of this paper and to Mrs Julie Morris for statistical advice.

\section{References}

BELANGER-ANNABLE. M. (1985) Long acting neuroleptics: technique for intramuscular injection. Canadian Nurse. 81. 1-3.

DAvis. J. M. (1974) Dose equivalence of the anti-psychotic drugs. Journal of Psychiatric Research, 11, 66-69.

FOSTER. P. (1989) Neuroleptic equivalence. Pharmaceutical Journal, 243, 431-432.

GlAZER. W. M. \& KANE. J. M. (1992) Depot neuroleptic treatment: an underutilised treatment option. Journal of Clinical Psychiatry, 53, 426-533.

GoTTFRIES, C. G. \& GREEN, L. (1974) Flupenthixol decanoate in treatment of out-patients. Acta Psychiatrica Scandinavica. 255 (suppl.), 15-23.

HamanN. G. L.. Egan. T. M.. Wells. B. G.. et al (1990) Injection site reactions after intramuscular administration of haloperidol decanoate $100 \mathrm{mg} / \mathrm{ml}$. Journal of Clinical Psychiatry. 51. 502-504.

HAY. J. (1995) Complications at site of injection of depot neuroleptics. British Medical Joumal, 311, 421.

HiRSCH. S. R., GAIND, R., RohDE, P. D., et al (1973) Outpatient maintenance of chronic schizophrenic patients with long-acting fluphenazine: Double blind placebo trial. British Medical Journal, i, 633-637.

McCreadie, R. G., Kiernan, W. E. S., Venner, R. M.. et al (1979) Probable toxic necrosis after prolonged fluspirilene administration. British Medical Journal. 1. 523-524.

StARMARK, J., FORSMAN, A. \& Wahlstrom, J. (1980) Abscesses following prolonged intramuscular administration of perphenazine enantate. Acta Psychiatrica Scandinavica. 62, 154-157.

SVENDSEN. O. (1989) Studies of Tissue Injuries Caused by Intramuscular Injection of Drugs and Vehicles. Methods for Quantification and Effects of Concentration. Volume. Vehicle. Injection Speed and Intralipomatous Injection. Copenhagen: Medicinsk-historisk Museum.

Julie C. Jones, Department of Psychiatry, University Hospital of South Manchester, Manchester; Jennifer C. Day. Department of Pharmaceutical Sciences, University of Nottingham, Nottingham; John R. Taylor, North Mersey Community Trust, Sefton General Hospital, Liverpool and "Christopher S. Thomas, Department of Psychiatry. University Hospital of South Manchester, Nell Lane. Manchester M20 8LR

*Correspondence 